\title{
LPV Feedforward Control of Semi-Active Suspensions for Improved Roll Stability
}

\author{
Michael Fleps-Dezasse ${ }^{\mathrm{a}, *}$,Tilman Bünte ${ }^{\mathrm{a}}$, Ferdinand Svaricek ${ }^{\mathrm{b}}$, Jonathan \\ Brembeck $^{\mathrm{a}}$ \\ ${ }^{a}$ German Aerospace Center, Institute of System Dynamics and Control, Münchnerstr. 20, \\ 82234 Weßling, Germany \\ ${ }^{b}$ University of the Federal Armed Forces, Institute of Control Engineering, Department of \\ Aerospace Engineering, 85577 Neubiberg, Germany
}

\begin{abstract}
This work augments an existing LPV feedback controller by a new LPV feedforward filter to improve the stability of a vehicle subject to driver-induced roll disturbances. In particular, the proposed LPV feedforward filter is designed by a Full-Information control approach and uses the saturation indicator concept to consider the restrictive state-dependent force constraints of semi-active dampers. Hence, in the event of saturation, the feedforward filter reduces its contribution to the control signal. The roll stability improvement due to the LPV feedforward filter is demonstrated by lane change experiments.

Keywords: vehicle dynamics, suspension control, actuator constraints, linear-parameter varying control, feedforward control
\end{abstract}

\section{Introduction}

Semi-active suspensions offer a large potential to improve essential vehicle properties like ride comfort, road-holding and handling compared to passive suspensions $([1,2])$. The exploitation of this potential relies on suitable semi-active 5 suspension control algorithms which consider the restrictive state-dependent ac-

\footnotetext{
* Corresponding author

Email addresses: michael.fleps-dezasse@dlr.de (Michael Fleps-Dezasse), tilman.buente@dlr.de (Tilman Bünte), ferdinand.svaricek@unibw.de (Ferdinand Svaricek), jonathan.brembeck@dlr.de (Jonathan Brembeck)
} 
tuator force limitations due to the passivity constraint of semi-active dampers. The optimal values of the design targets ride comfort and road-holding cannot be simultaneously achieved during suspension control design. Hence, the design always has to seek the best compromise between them ([3], 4] $)$. The two main disturbances to be attenuated by the semi-active suspension controller are road disturbances and driver-induced roll and pitch disturbances. These two disturbances have distinct frequency ranges meaning that the relevant frequency range of road disturbances is $0-20 \mathrm{~Hz}$, while the relevant frequency range of driverinduced disturbances is $0-3 \mathrm{~Hz}$. In most vehicle applications, road disturbances are unknown during runtime, but driver-induced disturbances can be estimated from the driver inputs by a planar vehicle model. The driver-induced disturbances considered in this work emerge from the steering inputs of the driver e.g. when driving on a curvy country road. They significantly affect ride comfort, road-holding and handling. As shown in [5, 6], controllers which minimize the effect of road disturbances only achieve medium ride comfort and road-holding regarding driver-induced disturbances and vice versa. The authors in 7] address the control design of an active suspension system in the presence of road disturbances and driver-induced disturbances by a special parametrization of an LTI controller for decoupled tuning of the two disturbance transmission paths.

25 Compared to road disturbances, driver-induced disturbances, however, feature the advantageous property that they can be estimated from the driver inputs and the vehicle states. This knowledge can be explored by a feedforward controller within a two-degree-of-freedom structure. The authors in [6] present a two-degree-of-freedom optimal LQ control design of an active suspension system which simultaneously considers road and driver-induced disturbances. In particular as mentioned above, the authors in [6] have observed that the LQ controller without feedforward shows a vital degradation of ride comfort and road-holding. In [8], the authors adjust their approach to semi-active suspensions and present experimental results of a cornering manoeuvre. Alternatively, the author in [9] 35 present a so-called steering input augmentation (SIA) of a Skyhook control such that the SIA-Skyhook controller increases its control signal proportional to the 
steering input. The roll stability enhancement of the SIA-Skyhook controller is then validated by lane change experiments.

In contrast to [6], this work pursues a feedforward-feedback decoupling ap40 proach as theoretically described in [10], i.e. the separate design of the feedforward and feedback paths. The two-step control design has the appealing property that the feedback controller can focus on attenuation of unknown disturbances and the feedforward filter can achieve fast tracking and rejection of known disturbances. Examples of LPV feedback controllers dedicated to at45 tenuate road disturbances are [11, 12]. These papers present a quarter-vehicle control approach based on polytopic LPV methods. The control design of [1]] relies on the appropriate selection of scheduling parameter-dependent weighting filters such that the final controller always stays within the actuator limits. In the follow-up research in [12], the polytopic LPV framework is use to ap${ }_{50}$ proximate the nonlinear damper by an LPV model and subsequently directly incorporate the LPV damper model in the quarter-vehicle plant model. In this way, parameter-dependent weighting filters are no longer mandatory and parameter-independent ones are used. The presented feedforward control design assumes a preexisting LPV feedback controller, which employs the saturation 55 indicator concept introduced in [13] to model the actuator force constraints in the LPV plant $([14,15])$. The proposed LPV feedforward filter can be obtained by solving a Full-Information (FI) problem. The FI control approach is simple and naturally extends to LPV plants as shown in [10]. Moreover the FI control approach can be applied to a multitude of feedforward design problems as 60 illustrated by the LPV helicopter control design application presented in [16] and the LPV missile control design example given in [17]. Regarding semiactive suspension control design, the FI control approach features the essential property that the saturation indicator concept is coherently applicable to the feedforward and feedback control design. In this way, the proposed feedforward

65 filter can be designed similar to an existing feedback controller such that the feedforward filter and the feedback controller equally reduce their control signal in the event of saturation according to the value of the saturation indicators. 
The resulting two-degree-of-freedom LPV controller attains guaranteed stability for all admissible actuator saturation conditions and good performance regarding both disturbances. The feedforward control design presented in this work focuses on shaping the body response of the vehicle subject to driver-induced roll disturbances. The feedforward filter takes the estimated lateral vehicle acceleration as input and generates appropriate damper forces. The estimation of the lateral vehicle acceleration is obtained from the steering angle and the vehicle speed using a single-track model. The effectiveness of the feedforward filter is emphasized by the simulation of a lane change scenario and by double lane change experiments with the SC3-Bulli (based on a VW T5 van) of the Institute of System Dynamics and Control (SR) of the German Aerospace Center (DLR) depicted in Fig. 1 .

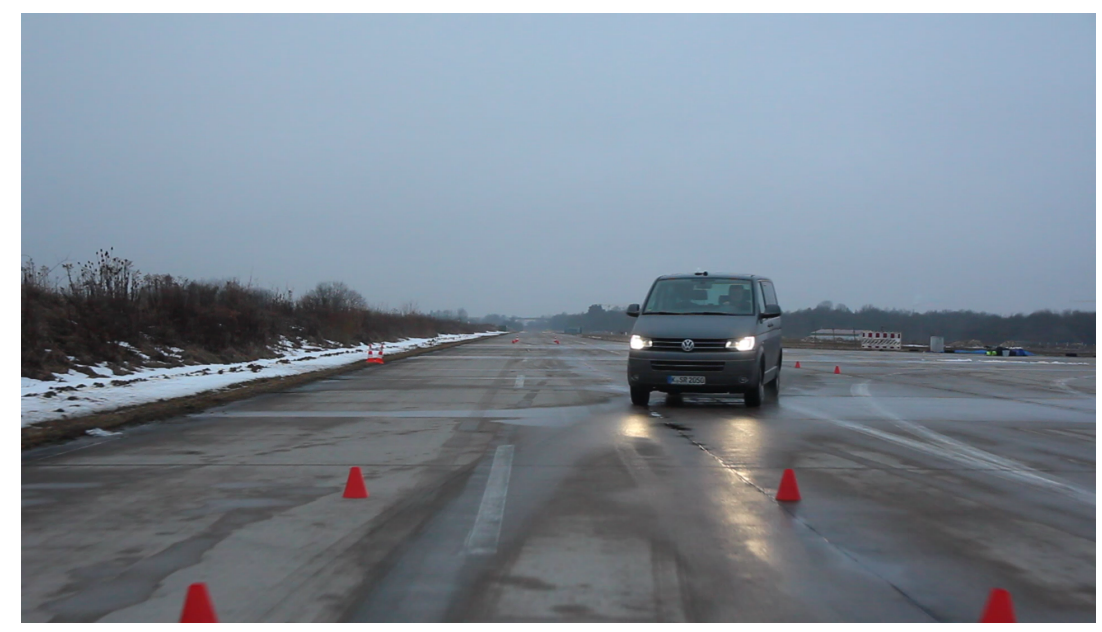

Figure 1: SC3-Bulli experimental vehicle on test track during double lane change manoeuvre

\section{Problem Statement}

This work addresses the feedforward control design of a full-vehicle equipped with four semi-active dampers. The control design target is the rejection of driver-induced body roll disturbances, while retaining the closed-loop road disturbance attenuation of a preexisting LPV feedback controller. Moreover, the 
resulting two-degree-of-freedom controller should firstly feature guaranteed stability for all admissible actuator saturation conditions. Secondly, the feedforward filter should not dominate the two-degree-of-freedom controller near the actuator constraints such that the feedforward filter and the feedback controller enjoy equal priority over the constrained control signal. The preexisting LPV

90 feedback controller is assumed according to [14, 15], i.e. to employ saturation indicator scheduling parameters to model the actuator force limits directly in the LPV plant [13]. Furthermore, the LPV feedback controller is assumed to linearly reduce its control signal depending on the saturation indicators.

A detailed introduction to LPV control design including recent developments 95 and many application examples can be found in [18, 19].

\subsection{LPV Modeling of Actuator Constraints}

The general control configuration of a closed-loop with actuator constraints is depicted in Fig. 22 The open-loop plant $\boldsymbol{G}_{\Theta}$ consists of the unconstrained open-loop LTI plant $\boldsymbol{G}$ and the saturation block. The control signals $\boldsymbol{u}$ of the LPV controller $\boldsymbol{K}_{\Theta}$ are fed into the saturation block yielding the saturated control signals $\boldsymbol{\sigma}(\boldsymbol{u})$. Based on the anti-windup LPV control approach of [13], the saturated control signal can be expressed by

$$
\boldsymbol{\sigma}(\boldsymbol{u})=\boldsymbol{\Theta} u
$$

with the saturation matrix given by $\boldsymbol{\Theta}=\operatorname{diag}(\boldsymbol{\theta})$. The saturation matrix gathers the saturation indicators of the individual actuators $\boldsymbol{\theta}=\left[\begin{array}{llll}\theta_{1} & \theta_{2} & \ldots & \theta_{n_{u}}\end{array}\right]^{T}$ under the assumption of decoupled actuator constraints, i.e. the control signal of one actuator has no influence on the saturated control signals of other actuators. The saturation indicator of the $i$-th actuator is defined as

$$
\theta_{i}=\left\{\begin{array}{cc}
\frac{\sigma\left(u_{i}\right)}{u_{i}} & u_{i} \neq 0 \\
1 & u_{i}=0
\end{array} \quad \forall i \in\left\{1,2 \ldots, n_{u}\right\}\right.
$$




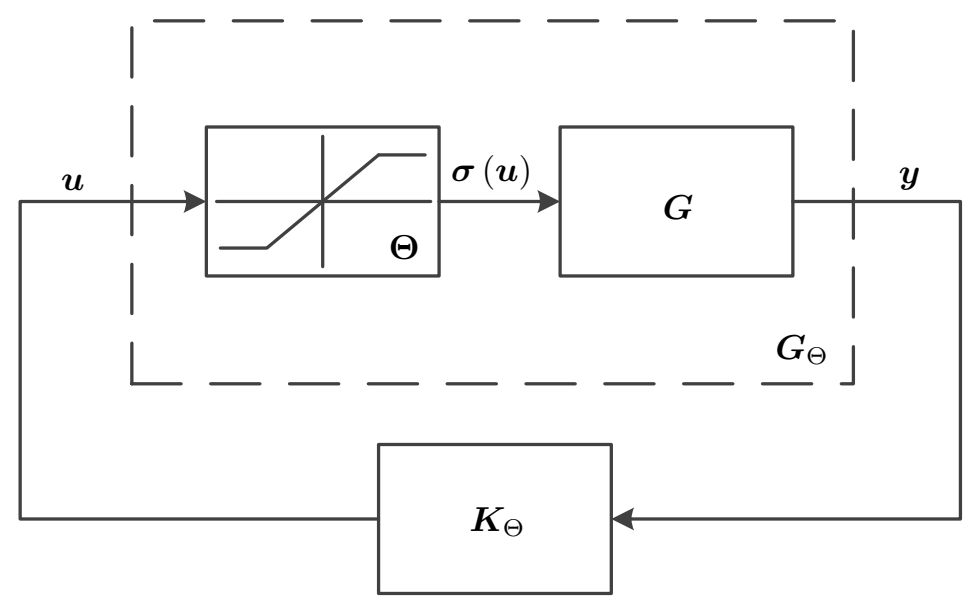

Figure 2: Closed-loop of plant $\boldsymbol{G}_{\Theta}$ with actuator saturation and controller $\boldsymbol{K}_{\Theta}$

with $n_{u}$ the number of actuators and the saturation function $\sigma\left(u_{i}\right)$ according to

$$
\sigma\left(u_{i}\right)=\left\{\begin{array}{cc}
u_{i} & u_{i}^{\min }<u_{i}<u_{i}^{\max } \\
u_{i}^{\min } & u_{i}^{\min } \geq u_{i} \\
u_{i}^{\max } & u_{i}^{\max } \leq u_{i}
\end{array}\right.
$$

The upper and lower limits are assumed $u_{i}^{\max }>0$ and $u_{i}^{\min }<0$, respectively, to achieve a proper actuator constraint representation by the saturation indicators. Moreover, during the LPV control design, the saturation indicators $\boldsymbol{\theta}$ are assumed to continuously evolve over time, to be either measurable or estimable in real-time, and to be bounded by $\theta_{i} \in(0,1] \forall i \in\left\{1,2 \ldots, n_{u}\right\}$. The unconstrained system, i.e. when the control signals can be realized by the actuators, is indicated by a saturation indicator value of one, and values smaller than one reflect the degree of saturation. The state-space realization of proper plants $\boldsymbol{G}_{\Theta}$ can then be stated by

$$
\left[\begin{array}{c}
\dot{\boldsymbol{x}} \\
\boldsymbol{y}
\end{array}\right]=\left[\begin{array}{cc}
\boldsymbol{A} & \overline{\boldsymbol{B}}_{2} \Theta \\
\boldsymbol{C}_{2} & \mathbf{0}
\end{array}\right]\left[\begin{array}{l}
\boldsymbol{x} \\
\boldsymbol{u}
\end{array}\right],
$$


with $\boldsymbol{A} \in \boldsymbol{R}^{n_{x} \times n_{x}}, \boldsymbol{B}_{2} \in \boldsymbol{R}^{n_{x} \times n_{u}}, \boldsymbol{C}_{2} \in \boldsymbol{R}^{n_{y} \times n_{x}}$, and the vectors $\boldsymbol{x}, \boldsymbol{y}$ and $\boldsymbol{u}$ of appropriate dimension.

\subsection{Vehicle Model with Roll Disturbance Input}

The behavior of the full-vehicle subject to driver-induced roll disturbances is modeled as proposed in [6] by introducing a roll moment disturbance input $d_{r}$ into the classical LTI full-vehicle model presented e.g. in [20]. In contrast to the design of the feedback controller in [14], however, the vehicle model with roll disturbance used in this work neglects the body heave and roll degrees-offreedom. This simplification exploits the property that the body heave and pitch degrees-of-freedom and the body roll degree-of-freedom are almost decoupled (1] ) such that body roll disturbances do not excite the body heave and pitch motion. Fig. 3 illustrates the front view of the vehicle model with roll degreeof-freedom and introduces the relevant notation. Accordingly, the equations of motion of the vehicle derived from Newton's second law are comprised of the equations of motion of the wheels given by

$$
\begin{array}{r}
m_{w, i} \ddot{x}_{w, i}=k_{b, i}\left(x_{b s, i}-x_{w, i}\right)+d_{0}\left(\dot{x}_{b s, i}-\dot{x}_{w, i}\right) \\
-k_{w} x_{w, i}-d_{w} \dot{x}_{w, i}-x_{F_{d}, i}
\end{array}
$$

with the index $i \in\{1,2,3,4\}$ denoting one of the four wheel unit, $x_{b s, i}$ the body position above the wheel contact point at the respective suspension unit, and the body roll degree-of-freedom given by

$$
\begin{array}{r}
I_{x x} \ddot{x}_{b, \mathrm{roll}}=d_{r}+\sum_{i} l_{\mathrm{roll}, i}\left(k_{b, i}\left(x_{w, i}-x_{b s, i}\right)+\right. \\
\left.d_{0}\left(\dot{x}_{w, i}-\dot{x}_{b s, i}\right)+x_{F_{d}, i}\right) .
\end{array}
$$

100 with the vector $l_{\text {roll }}=\left[l_{y, f} / 2-l_{y, f} / 2 l_{y, r} / 2-l_{y, r} / 2\right]^{T}$. The body positions $x_{b s, i}$ are calculated from the body roll angle $x_{b, \text { roll }}$ by a geometric transformation using small angle assumptions as described in [21]. The parameters $l_{y, f}$ and $l_{y, r}$ denote the $y$-distances from the center of gravity $(\mathrm{CoG}$ ) to the wheel units, respectively. The body spring stiffness at the front and rear suspensions 
105 are denoted by $k_{b, i}$. Eq. (5) and (6) cover the effect of driver-induced roll disturbances $d_{r}$ on the vehicle body, but neglect the additional transmission paths to the wheels. The roll moment distribution between both transmission paths is determined by the suspension kinematics, more precisely by the distance between the body center of gravity $(\mathrm{CoG})$ and the vehicle roll axis. Regarding semi-active suspension control, however, only the response of the vehicle body to roll disturbances can be essentially shaped by adjusting the damper forces.

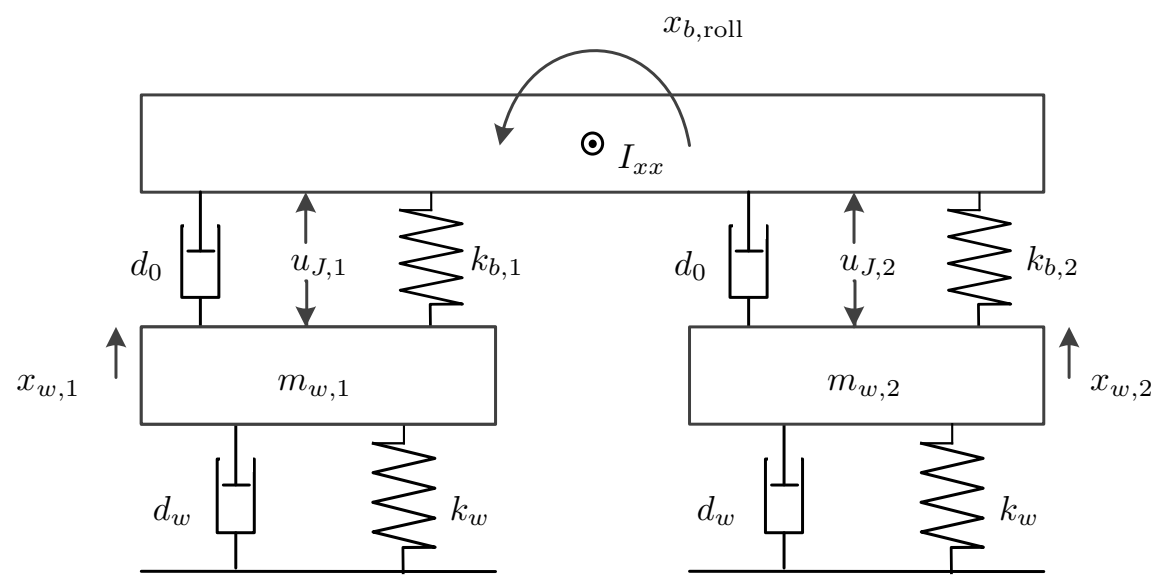

Figure 3: Front view of vehicle model with roll degree-of-freedom

The passivity constraint limits the damper forces $\boldsymbol{F}_{s a}$ to the first and third quadrant of the force-over-velocity-diagram of the damper. The asymmetry is obstructive for the modeling of the actuator force limits by saturation indicators in an LPV plant because the upper and lower force limits do not satisfy the assumptions $u_{i}^{\max }>0$ and $u_{i}^{\min }<0$. To obtain an eligible representation, the damper force $\boldsymbol{F}_{s a}$ is split into a virtual damper force $\boldsymbol{x}_{F_{d}}$ and a nominal damper force with damping coefficient $d_{0}$ according to

$$
F_{s a, i}=-d_{0} \dot{x}_{d, i}+x_{F_{d}, i}
$$

with $\dot{x}_{d, i}$ the velocity of damper $i$ such that the limits of the virtual damper force $\boldsymbol{x}_{F_{d}}$ satisfy the assumptions $u_{i}^{\max }>0$ and $u_{i}^{\min }<0$ of the saturation 
indicator concept. In general as discussed in [22], this transformation cannot be performed with a constant nominal damping $d_{0}$, however, in this work it is assumed that the force limits of the semi-active damper allow to perform the transformation with a constant nominal damping. A detailed discussion of this transformation can be found in [11, 22]. The dynamics of the virtual damper forces $\boldsymbol{x}_{F_{d}}$ depending on the control signals $\boldsymbol{u}_{F_{d}}$ is approximated by the first-order model

$$
\dot{x}_{F_{d}, i}=\omega_{d}\left(u_{J, i}-x_{F_{d}, i}\right) \text {, }
$$

with the actuator bandwidth $\omega_{d}$. The vehicle model $\boldsymbol{G}_{\Theta}$ with roll disturbance input can now be stated in state-space notation by

$$
\dot{\boldsymbol{x}}=\boldsymbol{A} \boldsymbol{x}+\boldsymbol{B}_{1} d_{r}+\overline{\boldsymbol{B}}_{2} \boldsymbol{\Theta} \boldsymbol{u}_{J},
$$

with the control input $\boldsymbol{u}_{J}$, the roll disturbance moment input $d_{r}$, the saturation indicator matrix $\boldsymbol{\Theta}$ and the state vector $\boldsymbol{x}$ given by

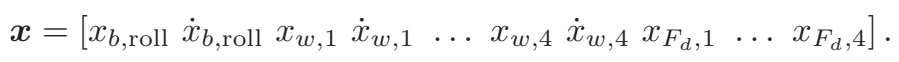

The roll disturbance moment $d_{r}$ acting on the vehicle body due to lateral vehicle accelerations can be computed from the lateral acceleration $a_{y S}$ according to

$$
d_{r}=t_{\mathrm{roll}} a_{y S}
$$

with the transmission factor $t_{\text {roll }}$ determined by

$$
t_{\mathrm{roll}}=-m_{b}\left(h_{b, C o G}-h_{\mathrm{roll}}\right) .
$$

The transmission factor $t_{\text {roll }}$ transforms the lateral acceleration into a lateral force acting on the vehicle body using the body mass $m_{b}$ and furthermore, into the roll disturbance moment through the lever arm between the point of 115 application of the lateral force and the vehicle roll axis. The lever arm of the lateral force corresponds to the vertical distance between the vehicle CoG and the roll axis $([1])$. 


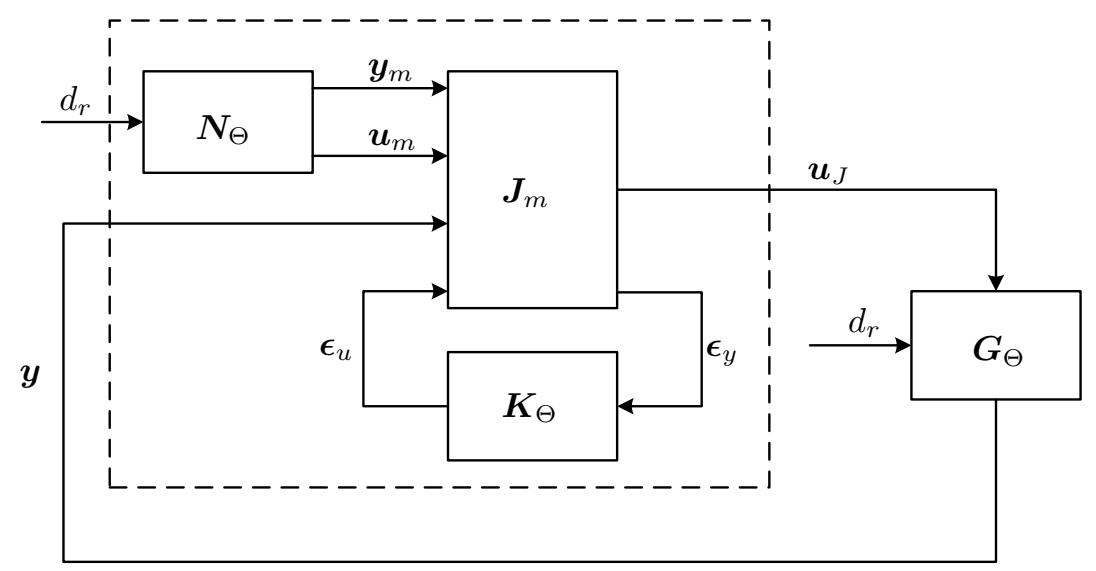

Figure 4: Two-degree-of-freedom closed-loop interconnection

\section{LPV Feedforward Filter Design}

The authors in [10] present the design of a feedforward filter by solving an FI problem. The FI problem represents a special type of control problem whose plant states and disturbances are available as measurements. For LTI systems, it is extensively discussed in [23] and 24] together with three corresponding special problems: the Disturbance-Feedforward (DF), the Full-Control (FC) and the Output-Estimation (OE) problem. The generalization to LPV systems

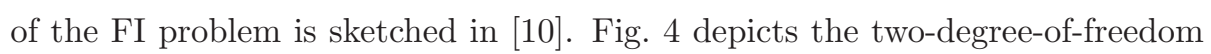
closed-loop interconnection consisting of the feedback controller $\boldsymbol{K}_{\Theta}$ and the feedforward filter $\boldsymbol{N}_{\Theta}$ with the vehicle model with roll disturbance input $\boldsymbol{G}_{\Theta}$. The feedforward filter and feedback controller are combined through the matrix $\boldsymbol{J}_{m}$ given by

$$
\boldsymbol{J}_{m}=\left[\begin{array}{cccc}
\mathbf{0} & \boldsymbol{I} & \mathbf{0} & \boldsymbol{I} \\
-\boldsymbol{I} & \mathbf{0} & \boldsymbol{I} & \mathbf{0}
\end{array}\right] .
$$

The feedforward filter $N_{\Theta}$ maps the roll disturbance input $d_{r}$ to the reference measurements $\boldsymbol{y}_{m}$ and the feedforward control signal $\boldsymbol{u}_{m}$. Starting from the solution of the FI problem, the feedforward filter $\boldsymbol{N}_{\Theta}$ is obtained as the inter- 
connection of the FI controller $\boldsymbol{K}_{F I}$ with system $\boldsymbol{P}_{N}$ according to

$$
\boldsymbol{N}_{\Theta}=\boldsymbol{\Gamma}\left(\boldsymbol{P}_{N}, \boldsymbol{K}_{F I}\right)
$$

with $\boldsymbol{P}_{N}$ given by

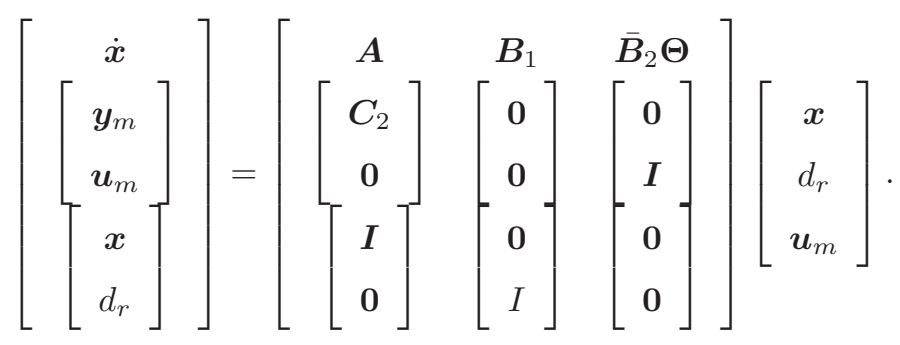

The system $\boldsymbol{P}_{N}$ particularly estimates the inputs of the FI controller $\boldsymbol{K}_{F I}$ from the roll disturbance input $d_{r}$ such that the control signal $\boldsymbol{u}_{m}$ of $\boldsymbol{K}_{F I}$ minimizes the effect of the disturbance $d_{r}$ on the plant $\boldsymbol{G}_{\Theta}$. Naturally, in the absence of disturbances $d_{r}$, the control structure of Fig. 4 recovers the closed-loop with pure feedback. Moreover, as discussed in [10], for a perfectly known plant and the reference measurements satisfying

$$
\boldsymbol{y}_{m}=\boldsymbol{G}_{\Theta}\left[\begin{array}{c}
\boldsymbol{u}_{m} \\
d_{r}
\end{array}\right],
$$

the control structure of Fig. 4 achieves perfect rejection of the known disturbances $d_{r}$. By perfect disturbance rejection it is meant that for zero-state initial condition, the reference measurements $\boldsymbol{y}_{m}$ of the feedforward filter equal the measurements $\boldsymbol{y}$ of $\boldsymbol{G}_{\Theta}$ and the control signal $\boldsymbol{u}$ of $\boldsymbol{G}_{\Theta}$ equals the control signal $\boldsymbol{u}_{m}$ of the feedforward filter. In case of different, non-zero state initial conditions of feedforward filter and plant, $\boldsymbol{y}$ and $\boldsymbol{u}$ will asymptotically tend towards $\boldsymbol{y}_{m}$ and $\boldsymbol{u}_{m}$, respectively.

The FI controller $\boldsymbol{K}_{F I}$ is determined by minimizing the induced $L_{2}$-norm of the closed-loop interconnection $\boldsymbol{\Gamma}\left(\boldsymbol{P}_{F I}, \boldsymbol{K}_{F I}\right)$. During the problem formulation, the original open-loop plant $\boldsymbol{G}_{\Theta}$ is augmented by input and output weighting filters to specify the desired closed-loop shape according to the two-stage loopshaping design process well-established in $\mathcal{H}_{\infty}$ control, see e.g. [25] and [26]. The resulting open-loop plant $\boldsymbol{P}_{F I}$ is often referred to as generalized open-loop 
plant. The induced $L_{2}$-norm from the disturbance $d_{r}$ to the performance signals $\boldsymbol{e}$ of LPV system $\boldsymbol{\Gamma}_{e d}\left(\boldsymbol{P}_{F I}, \boldsymbol{K}_{F I}\right)$ is defined as

$$
\begin{aligned}
& \left\|\boldsymbol{\Gamma}_{e d}\left(\boldsymbol{P}_{F I}, \boldsymbol{K}_{F I}\right)\right\|_{i 2}= \\
& \sup _{\theta_{i} \in(0,1] \forall i \in\left\{1,2 \ldots, n_{u}\right\},\left\|d_{r}\right\|_{2} \neq 0,} \frac{\left\|\boldsymbol{\Gamma}_{e d}\left(\boldsymbol{P}_{F I}, \boldsymbol{K}_{F I}\right) d_{r}\right\|_{2}}{\left\|d_{r}\right\|_{2}}<\gamma,
\end{aligned}
$$

with the induced $L_{2}$ performance level $\gamma$, and the conditions $\left\|d_{r}\right\|_{2} \neq 0$ and $d_{r} \in \mathcal{L}_{2}$ ensuring that the $L_{2}$-norm of the input signal $d_{r}$ is well defined. In accordance with [24], the generalized plant $\boldsymbol{P}_{F I}$ can then be expressed by

$$
\left[\begin{array}{c}
\dot{\boldsymbol{x}} \\
\boldsymbol{e} \\
{\left[\begin{array}{c}
\boldsymbol{x} \\
d_{r}
\end{array}\right]}
\end{array}\right]=\left[\begin{array}{ccc}
\boldsymbol{A}(\boldsymbol{\theta}) & \boldsymbol{B}_{1} & \overline{\boldsymbol{B}}_{2}(\boldsymbol{\theta}) \boldsymbol{\Theta} \\
\boldsymbol{C}_{1}(\boldsymbol{\theta}) & \mathbf{0} & \overline{\boldsymbol{D}}_{12}(\boldsymbol{\theta}) \boldsymbol{\Theta} \\
{\left[\begin{array}{l}
\boldsymbol{I} \\
\mathbf{0}
\end{array}\right]} & {\left[\begin{array}{l}
\mathbf{0} \\
I
\end{array}\right]} & {\left[\begin{array}{l}
\mathbf{0} \\
\mathbf{0}
\end{array}\right]}
\end{array}\right]\left[\begin{array}{c}
\boldsymbol{x} \\
d_{r} \\
\boldsymbol{u}_{m}
\end{array}\right] .
$$

The control design presented in this work, assumes proper generalized plants $\boldsymbol{P}_{F I}$ without direct feedthrough of the disturbances to the performance signals. As shown in 10], the control design for FI plants according to eq. (18) simplifies to a pure state-feedback control design. The optimal FI controller is then given by

$$
\boldsymbol{K}_{F I}=\left[\begin{array}{ll}
\boldsymbol{F}(\boldsymbol{\theta}) & 0
\end{array}\right] .
$$

with the state-feedback gain $\boldsymbol{F}(\boldsymbol{\theta})$ determined by the corresponding statefeedback problem with plant $\boldsymbol{P}_{x}$ and controller $\boldsymbol{K}_{x}$.

The controller synthesis is carried out in MATLAB using the LPVTools toolbox $([27,28])$. This toolbox formulates the LPV control problem as a group of linear matrix inequalities (LMI) of the performance index $\gamma$, the controller and the Lyapunov matrix $\boldsymbol{Z}([29,30,31])$. As part of the formulation of the optimization problem, the infinite-dimensional scheduling parameter space is approximated by a finite number of grid points. The resulting convex optimization problem can be stated by

$$
\begin{array}{rr}
\min _{\gamma, \boldsymbol{K}_{x}, \boldsymbol{Z}} \gamma & \text { s. t. } \\
\left\|\boldsymbol{\Gamma}\left(\boldsymbol{P}_{x}, \boldsymbol{K}_{x}\right)\right\|_{i 2}<\gamma & \forall \boldsymbol{\theta}=\left\{\boldsymbol{v}_{1}, \boldsymbol{v}_{2}, \ldots, \boldsymbol{v}_{n_{g}}\right\},
\end{array}
$$


with the grid points $\boldsymbol{v}_{i}$ and $n_{g}$ the number of grid points. The feedforward filter design presented later on is performed with a scheduling parameter-independent

\section{Roll Disturbance Feedforward Control Design}

The objective of the feedforward control design is the rejection of driverinduced roll disturbances. The performance criteria are ride comfort, roadholding and vehicle handling. In a full-vehicle context ride comfort can be characterized according to ISO 2631-1:1997 ([32]) by the vehicle body heave, roll and pitch accelerations. The body heave and pitch motion are only weakly excited by the considered roll disturbances and can be neglected during the computation of the ride comfort criteria $J_{c}$. The simplified criterion is then given by

$$
J_{c}=\sqrt{\frac{1}{T} \int_{0}^{T}\left|\ddot{\bar{x}}_{b, \text { roll }}(t)\right|^{2} d t .}
$$

The bar in (21) indicates that the RMS value of the body roll acceleration is computed after filtering the signal by the weighting filter given in [32]. The road-holding properties of a vehicle can be determined from the RMS value of the vectorial dynamic wheel load signal $\boldsymbol{F}_{w l}$. As described in [26], the RMS criterion can be computed by

$$
J_{r h}=\sqrt{\frac{1}{T} \int_{0}^{T} \sum_{p}\left|F_{w l, p}(t)\right|^{2} d t},
$$

with $p$ the number of elements of $\boldsymbol{F}_{w l}$ and $T$ the sequence length.

The vehicle handling properties can be only indirectly affected by semi-active suspension control. The authors in 33] discuss the contribution of suspension control which results from a reduction of the (dynamic) wheel load transfer. In particular, [33] argue that the lateral force capabilities of an axle decreases due to the wheel load transfer during cornering. The main reason for this effect is the degressive side force characteristic of tires. Hence, the increase in side force due to the higher wheel load of one tire of the axle is smaller than the decrease in 
side force due to the lower wheel load of the other tire of the axle. Consequently, a high (dynamic) wheel load transfer increases the side slip angles of the tires and reduces the maximum side force capabilities of the vehicle. The driver then has to compensate the large side slip angles of the tires by his steering input. The RMS value $J_{h}$ of the steering wheel angle $\delta_{F}$ given by

$$
J_{h}=\sqrt{\frac{1}{T} \int_{0}^{T}\left|\delta_{F}(t)\right|^{2} d t},
$$

is thus a good indicator of the vehicle handling properties.

As shown in the previous section, the feedforward filter can be designed by 135 solving an FI control problem. In the semi-active suspension control design considered in this work, the aim of the feedforward filter is to enhance ride comfort, road-holding and handling of the vehicle subject to driver-induced roll disturbances. Fortunately, these three design targets can be simultaneously realized by the feedforward filter as their individual design specification are largely compatible. With respect to vehicle handling, the steering wheel angle would be the first choice as perfromance signal, unfortunately, the steering wheel angle is not part of the FI control design problem with vehicle model $\boldsymbol{G}_{\Theta}$. As discussed above, however, vehicle handling can be improved by a reduction of the load transfer which is directly correlated to the body roll motion. During 145 the FI control design, the body roll velocity is employed as performance signal. The roll velocity sufficiently emphasizes the body roll resonance peak and offers a better roll-off than the roll acceleration. Compared to the roll angle, the roll velocity features a zero steady-state gain with respect to the roll disturbance input $d_{r}$. This is an essential property during the feedforward filter design of a semi-active suspension because the dampers have zero steady-state force capability.

The body roll velocity performance signal is weighted by the saturation indicator dependent weight $W_{a}(\boldsymbol{\theta})$ given by

$$
W_{a}(\boldsymbol{\theta})=w_{b, \text { roll }}\left(\frac{1}{n_{u}} \sum_{i=1}^{n_{u}} \theta_{i}\right) G_{p t 1},
$$




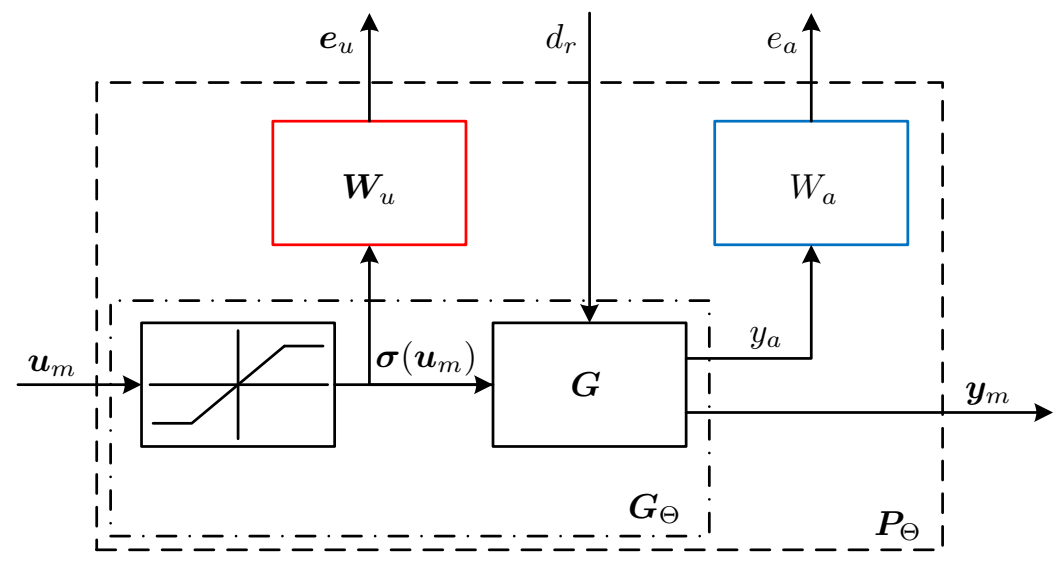

Figure 5: Weighting scheme of feedforward control design

with the scaling factor $w_{b, \text { roll }}$ and the first-order low-pass filter $G_{p t 1}$ with a cutoff frequency of $\omega_{p t 1}=10 \mathrm{~Hz}$. The saturation indicator dependence of $W_{a}(\boldsymbol{\theta})$ is realized such that the performance signal is scaled by the mean value of the saturation indicators $\boldsymbol{\theta}$ equally to the feedback control design in [14]. In this way, the performance requirement is relaxed if the actuators are saturated. The control effort weighting function $\boldsymbol{W}_{u}(\boldsymbol{\theta})$ given by

$$
\boldsymbol{W}_{u}(\boldsymbol{\theta})=\boldsymbol{\Theta}^{-1},
$$

is also realized as introduced in [14] such that the feedforward filter achieves the desired behavior, i.e the controller reduces its output with increasing actuator saturation. Fig. 5 illustrates the weighting scheme of the feedforward filter design with the roll disturbance model $\boldsymbol{G}_{\Theta}$ comprised of the saturation block and the unconstrained roll disturbance model $\boldsymbol{G}$ similar to Fig. 2. The plant $\boldsymbol{P}_{\Theta}$ gathering the vehicle model $\boldsymbol{G}_{\Theta}$ and the weighting functions $W_{a}(\boldsymbol{\theta})$ and 
$\boldsymbol{W}_{u}(\boldsymbol{\theta})$ can be stated by

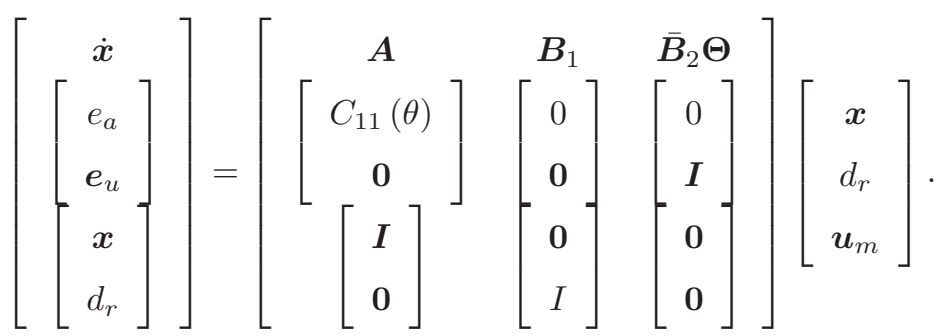

As discussed in the previous Section, the feedforward filter corresponding to the FI problem (26) can be designed via a state-feedback controller synthesis if the disturbances $d_{r}$ have no direct feedthrough to the performance signals $e_{a}$ and $\boldsymbol{e}_{u}$. The proposed feedforward filter design with $\boldsymbol{W}_{u}(\boldsymbol{\theta})$ and $W_{a}(\boldsymbol{\theta})$ always satisfies this condition. The corresponding state-feedback gain $\boldsymbol{F}(\boldsymbol{\theta})$ is given by

$$
\boldsymbol{F}(\boldsymbol{\theta})=-\gamma^{2} \boldsymbol{\Theta} \overline{\boldsymbol{B}}_{2}^{T} \boldsymbol{Z}
$$

with Lyapunov matrix $\boldsymbol{Z}$.

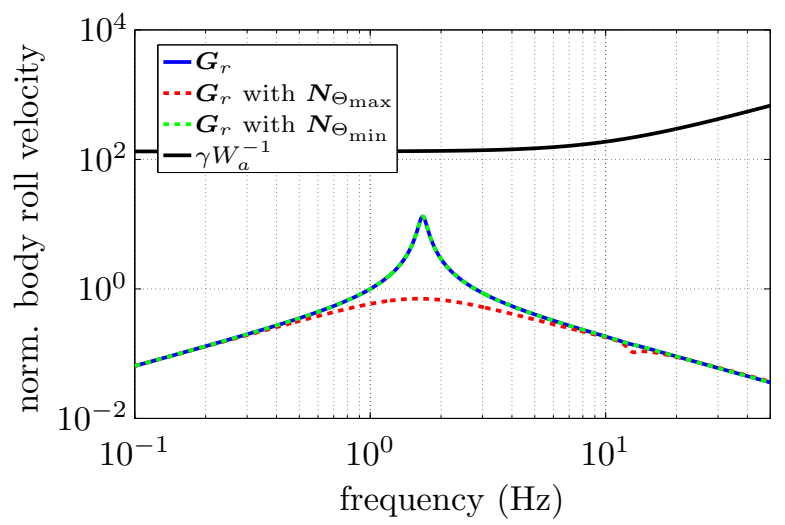

Figure 6: Frequency response of body roll velocity of $\boldsymbol{G}_{\Theta}$ without and with feedforward filter $N_{\Theta}$

Fig. 6 illustrates the frequency response of the roll velocity of the interconnection of the vehicle model $\boldsymbol{G}_{\Theta}$ with feedforward filter $\boldsymbol{N}_{\Theta}$ for the grid points ${ }_{155} \boldsymbol{\theta}=\boldsymbol{\theta}_{\min }$ and $\boldsymbol{\theta}=\boldsymbol{\theta}_{\max }$. According to the design specification, the feedforward filter with $\boldsymbol{\theta}=\boldsymbol{\theta}_{\max }$ significantly reduces the roll velocity resonance peak 
of the vehicle, while the response of the vehicle with feedforward filter with $\boldsymbol{\theta}=\boldsymbol{\theta}_{\min }$ resembles the open-loop system. According to the state-feedback gain (27) the control signal $\boldsymbol{u}_{m}$ of the feedforward filter is linearly reduced according to the value of the saturation indicators $\boldsymbol{\theta}$ until the effect of the feedforward filter vanishes and the frequency responses with and without feedforward filter coincide. Due to the equal saturation indicator dependent weighting schemes of the feedback and feedforward control design, the feedback and feedforward control signals are equally reduced in the event of saturation according to the saturation indicators and the two-degree-of-freedom controller achieves guaranteed stability for all admissible saturation indicators. Furthermore, the feedback controller and the feedforward filter feature equal priority over the constrained control signal such that the feedforward filter does not dominate the constrained closed-loop system.

\section{Validation of the Feedforward Filter Design}

The proposed feedforward filter is validated by simulation investigations and double lane change experiments with SR's SC3-Bulli. The experimental vehicle is equipped with the semi-active dampers from its successor model, namely the VW T6 van, where they are offered as supplemental equipment. Fig. 7 shows the normalized minimum and maximum force characteristics of the front and rear semi-active dampers in a force-over-velocity diagram. Both damper characteristics feature asymmetrical compression and rebound forces and a nonlinear force-over-velocity relationship. Due to the large payload of the experimental vehicle, especially the rear dampers have large rebound forces to provide suffi-

180 cient damping at maximum payload. The current of the electromagnetic valve of each damper is controlled by a PI controller with anti-windup. A current of $u_{d}=0.1 \mathrm{~A}$ corresponds to minimum damping and a current of $u_{d}=1.4 \mathrm{~A}$ to maximum damping. Fig. 8 shows the spring characteristics of the front and rear suspensions. To prevent large suspension strokes and minimize bump stop interferences at maximum payload, the rear springs feature a stiffer and 


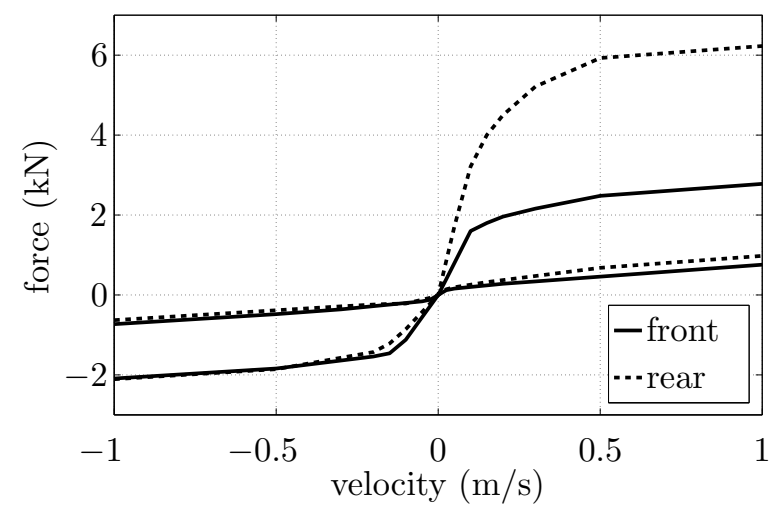

Figure 7: Semi-active damper characteristic of the SC3-Bulli

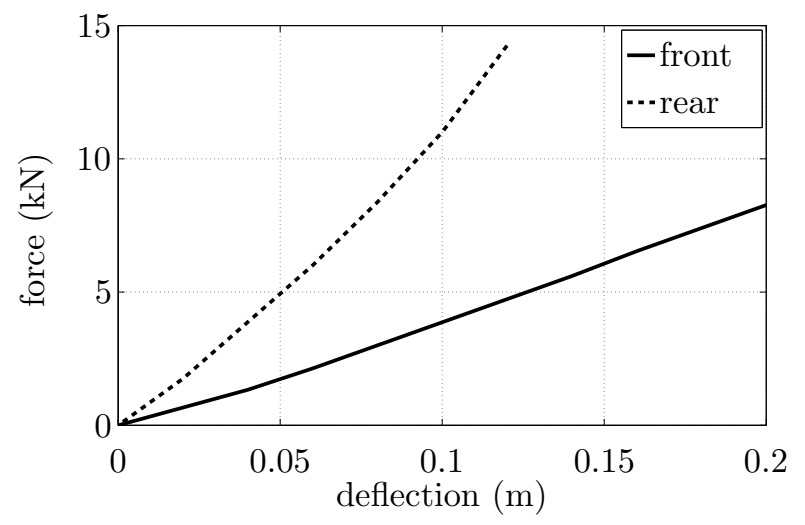

Figure 8: Body spring characteristic of SC3-Bulli

more progressive characteristic than the front springs. The front axle of the SC3-Bulli is realized by classical McPherson suspensions with the semi-active damper mounted inside the body spring and the rear suspensions are realized by transverse control arms. Table 1 gathers the parameters of the SC3-Bulli.

The SC3-Bulli is equipped with a dSPACE MicroAutoBox II which runs the semi-active suspension control algorithm at a sample time $T_{s}=0.5 \mathrm{~ms}$. An inverse damper model transforms the damper force demand generated by the controller into the current demand of the damper $([14,20])$. The damper demand signals calculated on the MicroAutoBox are then processed by a power 
Table 1: Symbols and parameters of SC3-Bulli vehicle model

\begin{tabular}{cccc} 
Symbol & Quantity & Value & Unit \\
\hline$m_{b}$ & body mass & 2400 & $\mathrm{~kg}$ \\
$I_{x x}$ & roll inertia & 850 & $\mathrm{kgm}^{2}$ \\
$m_{w}$ & wheel mass & 50 & $\mathrm{~kg}$ \\
$k_{w}$ & tire stiffness & 280 & $\mathrm{kN} / \mathrm{m}$ \\
$d_{w}$ & tire damping & 300 & $\mathrm{Ns} / \mathrm{m}$ \\
$\omega_{d}$ & damper bandwidth & 80 & $\mathrm{~Hz}$ \\
\hline
\end{tabular}

electronics unit. The power electronics generates the current of the electromagnetic valves and provides current measurements to the MicroAutoBox. As input signals to the control algorithms, the SC3-Bulli offers wheel acceleration, suspension height, body acceleration, vehicle velocity, and steering wheel angle measurements.

The nonlinear simulation model of the SC3-Bulli is implemented in Modelica (34]). The model is used for Desktop simulation of the closed-loop behavior and for controller tuning. The model includes most essential nonlinearities like

- the semi-active dampers,

- the nonlinear spring characteristics, and

- the transmission between wheel position and spring and damper deflections,

but neglects the stabilizer bars, the elastokinematics of the suspension systems and the bump stops due to missing component information. Furthermore, the nonlinear full-vehicle model approximates the tires by linear spring-damper elements and features no planar vehicle motions like yaw and longitudinal or lateral displacements. Equally to the linear vehicle model of Section 2.2, the ef- 
fect of lateral accelerations on the vehicle body is modeled by a roll disturbance moment acting on the body.

\subsection{Lane Change Simulations}

To verify the performance benefit of the two-degree-of-freedom controller with feedforward filter $\boldsymbol{N}_{\Theta}$, this section investigates an open-loop lane-change scenario. The vehicle model is excited by the lateral acceleration depicted in Fig 9- top. The roll disturbance moment resulting from the lateral acceleration is computed according to (12).

The two-degree-of-freedom LPV controller is compared to a comfort-oriented and a sporty passive suspension configuration. Additionally, the steering input augmentation of a Skyhook-Groundhook controller presented in [9] is adjusted to the case of an acceleration input. Compared to the steering angle, the lateral acceleration is directly correlated to the disturbance acting on the vehicle. Furthermore, as discussed in [9], the vehicle response to steering angle inputs is very sensitive to the vehicle speed, while the lateral acceleration represents the vehicle response. The control signal of the Skyhook-Groundhook controller with acceleration input augmentation (AIA), called SH/GH AIA, can be stated by

$$
\boldsymbol{u}_{J, A I A}=\frac{\boldsymbol{u}_{S H}\left(1-\operatorname{sign}\left(\left|a_{y S}\right|-a_{y, t h}\right)\right)}{2}+\frac{\boldsymbol{K}_{A I A} a_{y S}\left(1+\operatorname{sign}\left(\left|a_{y S}\right|-a_{y, t h}\right)\right)}{2},
$$

with $\boldsymbol{u}_{S H}$ the original Skyhook-Groundhook control signal as described in [20]. If the lateral acceleration $a_{y S}$ is smaller than the lateral acceleration threshold $a_{y, t h}$, the output of the SH/GH AIA controller is just the Skyhook-Groundhook control signal. However, if the lateral acceleration exceeds its threshold the second term gets active and the output of the $\mathrm{SH} / \mathrm{GH}$ AIA controller is proportional to the lateral acceleration. The gain $\boldsymbol{K}_{A I A}=k_{A I A}\left[\begin{array}{llll}-1 & 1 & -1 & 1\end{array}\right]^{T}$ scales the lateral acceleration to the desired damper force and distributes the force to the four dampers of the vehicle.

Table 2 presents the results of the simulation scenario. In addition to the criteria ride comfort and road-holding employed during feedback control design, 
Table 2: Performance assessment of two-degree-of-freedom controller with feedforward filter during simulation of lane-change scenario

\begin{tabular}{ccccc} 
& $\begin{array}{c}\text { ride } \\
\text { comfort }\end{array}$ & $\begin{array}{c}\text { road } \\
\text { holding }\end{array}$ & $\begin{array}{c}\text { roll } \\
\text { angle }\end{array}$ & $\begin{array}{c}\text { roll } \\
\text { velocity }\end{array}$ \\
& $J_{\text {cISO }}$ & $J_{r h}$ & RMS & RMS \\
\hline const. $\boldsymbol{u}_{d}$ comfort & $100 \%$ & $100 \%$ & $100 \%$ & $100 \%$ \\
const. $\boldsymbol{u}_{d}$ sport & $64 \%$ & $77 \%$ & $67 \%$ & $63 \%$ \\
SH $/$ GH AIA & $69 \%$ & $82 \%$ & $75 \%$ & $71 \%$ \\
LPV FVM ctrl & $71 \%$ & $82 \%$ & $78 \%$ & $73 \%$ \\
LPV FVM & $57 \%$ & $74 \%$ & $61 \%$ & $57 \%$ \\
ctrl with $\boldsymbol{N}_{\Theta}$ & & & & \\
\hline
\end{tabular}

230 the evaluation of the controller performance considers the RMS values of the roll angle and roll velocity of the vehicle body. In contrast to the investigation with road disturbances [14], the comfort-oriented passive suspension configuration (which applies $0.31 \mathrm{~A}$ front and $0.58 \mathrm{~A}$ rear) achieves the worst performance throughout all four criteria. At first glance, especially the bad ride comfort performance is surprising because the comfort-oriented passive suspension has been tuned to achieve good ride comfort. Unfortunately, good ride comfort regarding road disturbances and driver-induced disturbances corresponds to different passive damper configurations. This is further emphasized by the very good performance of the sporty-oriented passive suspension configuration (which applies $0.58 \mathrm{~A}$ front and $0.88 \mathrm{~A}$ rear). The behaviour can be justified by two reasons:

1. the transmission path of driver-induced disturbances to the body roll velocity shows a much better roll-off after the body resonance frequency (Fig. 6) than the transmission path of road disturbances, and

2. the driver-induced disturbances are mainly low frequency disturbances up to $3 \mathrm{~Hz}$. 

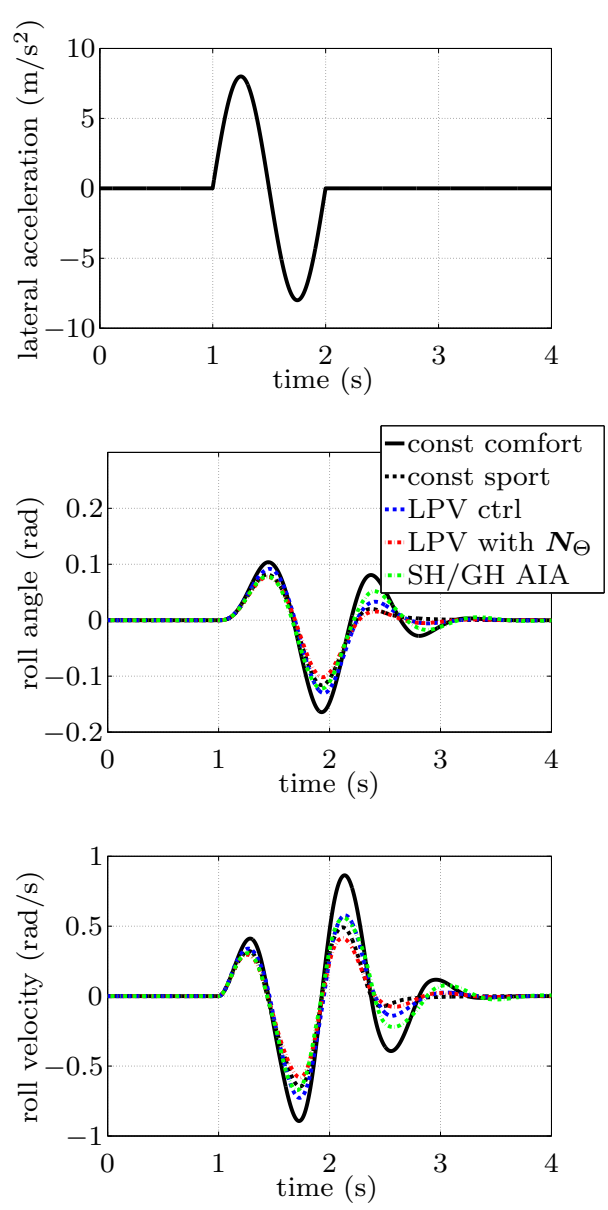

Figure 9: Open loop lane change simulation; top - lateral acceleration, middle - body roll angle, and bottom - body roll velocity

Accordingly, the LPV FVM feedback controller tuned for good ride comfort regarding road disturbances, shows only medium performance regarding driverinduced disturbances. This is overcome by the two-degree-of-freedom LPV FVM controller with feedforward filter $\boldsymbol{N}_{\Theta}$, which improves the ride comfort and the RMS criteria of the roll angle and the roll velocity by at least $14 \%$, and road-holding by $8 \%$ compared to the LPV controller without feedforward filter. Moreover, the LPV FVM controller with $\boldsymbol{N}_{\Theta}$ achieves a slightly better performance than the sporty passive suspension configuration. The two-degreeof-freedom LPV controller also performs significantly better than the $\mathrm{SH} / \mathrm{GH}$ 

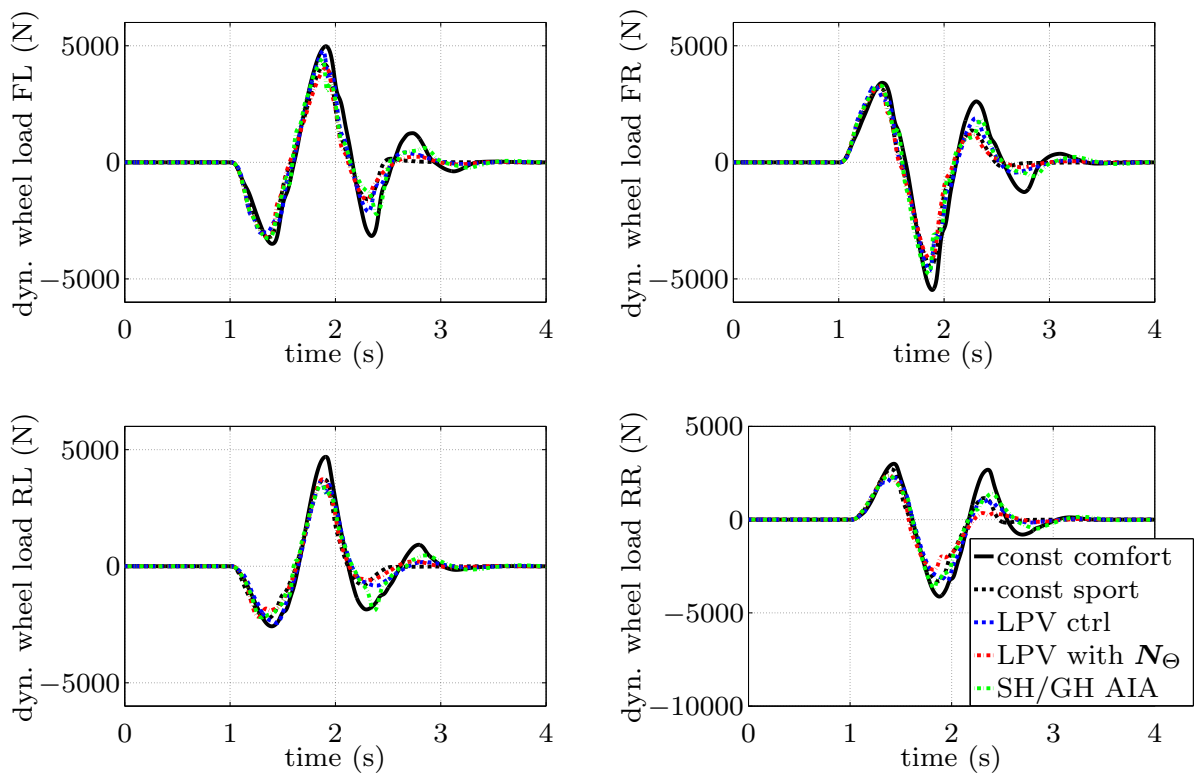

Figure 10: Open loop lane change simulation; top left - dyn. wheel load front left, top right dyn. wheel load front right, bottom left - dyn. wheel load rear left, and bottom right - dyn. wheel load rear right

AIA controller. Fig. 9-11illustrate the results of Table 2 by time series plots of the body roll angle, body roll velocity, dynamic wheel loads and control signals. As suggested by the results of Table 2 the sporty passive suspension configuration and the LPV controller with $\boldsymbol{N}_{\Theta}$ achieve the smallest roll angles and roll angle velocities. The figures particularly emphasize the main limitation of the $\mathrm{SH} / \mathrm{GH}$ AIA controller. Its feedforward control signal is proportional to the lateral acceleration and thus only active in the time range from 1 to $2 \mathrm{~s}$. The vehicle roll response, however, exhibits a transient behaviour and lasts until $3 \mathrm{~s}$. Therefore, the Skyhook-Groundhook controller has to take care of the vehicle response from $2 \mathrm{~s}$ onwards. As a consequence, the provided damper forces are too small and the vehicle roll response shows a larger amplitude.

The effect of the feedforward filter $\boldsymbol{N}_{\Theta}$ is particularly obvious from the control signals depicted in Fig. 11. Due to the feedforward filter $\boldsymbol{N}_{\Theta}$, the LPV controller with $\boldsymbol{N}_{\Theta}$ commands much higher control signals and stabilizes the 

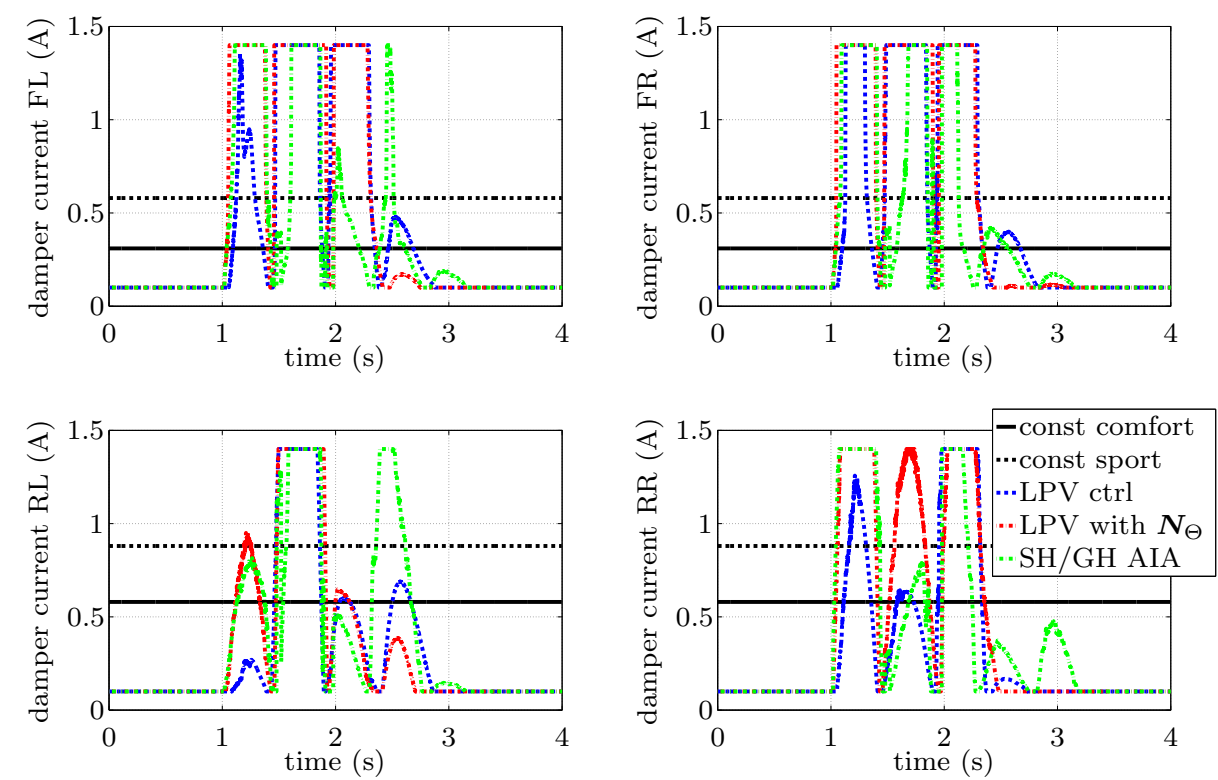

Figure 11: Open loop lane change simulation; top left - control signal front left, top right - control signal front right, bottom left - control signal rear left, and bottom right - control signal rear right

body roll motion. The control signals of the rear suspensions additionally visualize the vital asymmetry of the force map of the rear semi-active dampers, which provide large rebound forces and only small compression forces. Therefore, the commanded damper current during compression is much higher than during rebound operation of the dampers.

The results reveal that the feedforward filters could be parametrized even more aggressive to further improve the performance regarding driver-induced disturbances. During combined road and driver-induced disturbances, however, an aggressive feedforward filter reduces the overall performance of the LPV controller.

\subsection{Double Lane Change Experiments}

The double lane change manoeuvres are set-up according to ISO 3888-2:2011

(35]). The corresponding test track and parameters are given in Fig. 12 and 
Table 3. The lane change defined by 35] resembles an obstacle avoidance manoeuvre and is performed at a vehicle speed of $50 \mathrm{~km} / \mathrm{h}$.

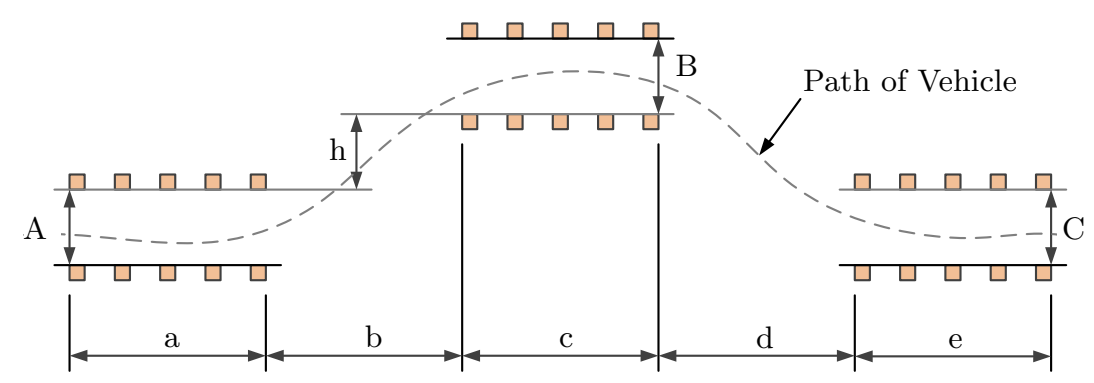

Figure 12: Experiment set-up according to ISO 3888 lane change

Table 3: Parameters of lane change manoeuvres according to ISO 3888-2:2011; all quantities in $(\mathrm{m})$

\begin{tabular}{ccccccccc}
\hline $\mathrm{a}$ & $\mathrm{b}$ & $\mathrm{c}$ & $\mathrm{d}$ & $\mathrm{e}$ & $\mathrm{A}$ & $\mathrm{B}$ & $\mathrm{C}$ & $\mathrm{h}$ \\
\hline 12 & 13.5 & 11 & 12.5 & 12 & $1.1 b_{v}+0.25$ & $b_{v}+1$ & 3 & 1 \\
\hline
\end{tabular}

The roll disturbance acting on the vehicle is estimated according to (12). The lateral acceleration needed as input to (12) is obtained by a linear single track model processing the steering angle input of the driver. Detailed presentations of the linear single track model are given in [1, 36]. The single track model has been parametrized with the lateral acceleration and yaw rate measurements of two reference manoeuvres: firstly a constant radius cornering with increasing vehicle speed and secondly a manoeuvre consisting of several steering angle step inputs at a constant vehicle velocity. Fig. 13illustrate the measured lateral acceleration and the estimated lateral acceleration of the single track model (STM) of the experiment with the passive suspension configuration const. $\boldsymbol{u}_{d}$ comfort. The figure provides a cross-validation of the performance of the single-track model 295 and confirms its suitability to predict the vehicle lateral acceleration. 


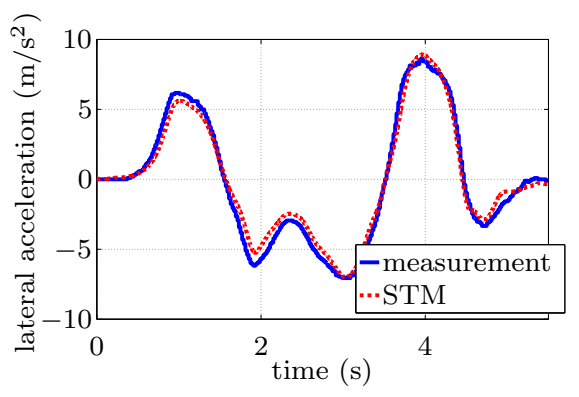

Figure 13: ISO3888-2: Double lane change at a vehicle speed of $50 \mathrm{~km} / \mathrm{h}$; single-track model estimation

Fig. 14 shows the measured lateral accelerations and steering angles of the four suspension configurations const. $\boldsymbol{u}_{d}$ comfort, const. $\boldsymbol{u}_{d}$ sport, LPV ctrl and LPV ctrl with feedforward filter $\boldsymbol{N}_{\Theta}$ of the double lane change manoeuvre. Throughout all four runs, the lateral accelerations and steering angles match very well during the first $2.5 \mathrm{~s}$ of the experiments. The vehicle with const. $\boldsymbol{u}_{d}$ sport and LPV ctrl with feedforward filter $\boldsymbol{N}_{\Theta}$, however, are essentially easier to drive due to the reduced body roll motion and less steering angle is needed by the driver from $2.5 \mathrm{~s}$ onwards to the end of the manoeuvre. This behavior is consistent with the discussion of the vehicle handling properties in Section 4. The attenuation of the body roll motion reduces the dynamics wheel load transfer and consequently the tire side slip angles during the lane change manoeuvre. Simultaneously, the resulting lateral acceleration and the roll disturbance are also smaller. This behaviour further enhances the performance of the suspension configurations const. $\boldsymbol{u}_{d}$ sport and LPV control with feedforward filter $\boldsymbol{N}_{\Theta}$. Table 4 gives a comparison of ride comfort and the RMS values of the body roll angle, the body roll velocity and the steering angle of the ISO 3888-2:2011 lane change manoeuvre. Compared to the LPV control without feedforward filter, the two-degree-of-freedom controller improves ride comfort by $15 \%$ and reduces the RMS values of the body roll angle and velocity by the same magnitude. Moreover, the RMS value of the steering angle is also reduced by about $20 \%$. Fig. 15illustrates the corresponding body roll angle and velocity 
Table 4: ISO3888-2: Double lane change at a vehicle speed of $50 \mathrm{~km} / \mathrm{h}$; performance assessment of two-degree-of-freedom controller with feedforward filter

\begin{tabular}{ccccc}
\hline & ride & roll & roll \\
& comfort & angle & velocity & angle \\
& $J_{\text {cISO }}$ & RMS & RMS & RMS \\
\hline const. $\boldsymbol{u}_{d}$ comfort & $100 \%$ & $100 \%$ & $100 \%$ & $100 \%$ \\
const. $\boldsymbol{u}_{d}$ sport & $88 \%$ & $78 \%$ & $81 \%$ & $84 \%$ \\
LPV FVM ctrl & $94 \%$ & $97 \%$ & $96 \%$ & $91 \%$ \\
LPV FVM & $79 \%$ & $76 \%$ & $81 \%$ & $78 \%$ \\
ctrl with $\boldsymbol{N}_{\Theta}$ & & & & \\
\hline
\end{tabular}

of the four configurations and Fig. 16] shows the damper current. As expected, the two-degree-of-freedom controller commands much higher control signals to attenuate the roll disturbance.

In summary, the results of the double lane change manoeuvre correspond well to the simulation results of Section 5.1, Even though the paths of the vehicle through the test track vary from experimental run to run due to imperfect driver inputs, the individual runs have just small variation of the lateral acceleration at the beginning of the experiment. Moreover, the LPV controller with feedforward 325 filter features a vital improvement of ride comfort up to $15 \%$ compared to the LPV controller without feedforward filter. This improvement is distinctly larger than the ride comfort variation due to the imperfect driver input of experimental runs with the same suspension configuration.

\section{Conclusion}

This paper augments a preexisting full-vehicle LPV controller by an LPV feedforward filter. The feedforward filter is designed by a Full-Information prob- 

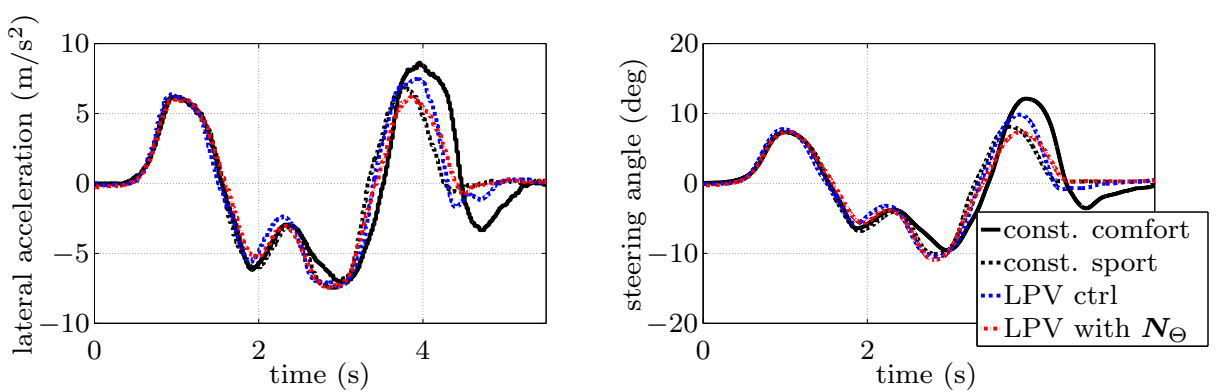

Figure 14: ISO3888-2: Double lane change at a vehicle speed of $50 \mathrm{~km} / \mathrm{h}$; left - lateral acceleration, and right - front wheel steering angle
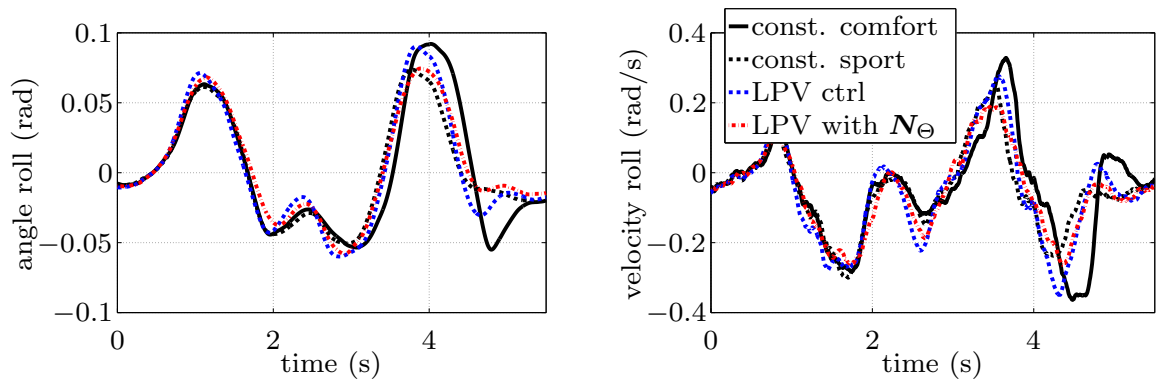

Figure 15: ISO3888-2: Double lane change at a vehicle speed of $50 \mathrm{~km} / \mathrm{h}$; left - body roll angle, right - body angular roll velocity 

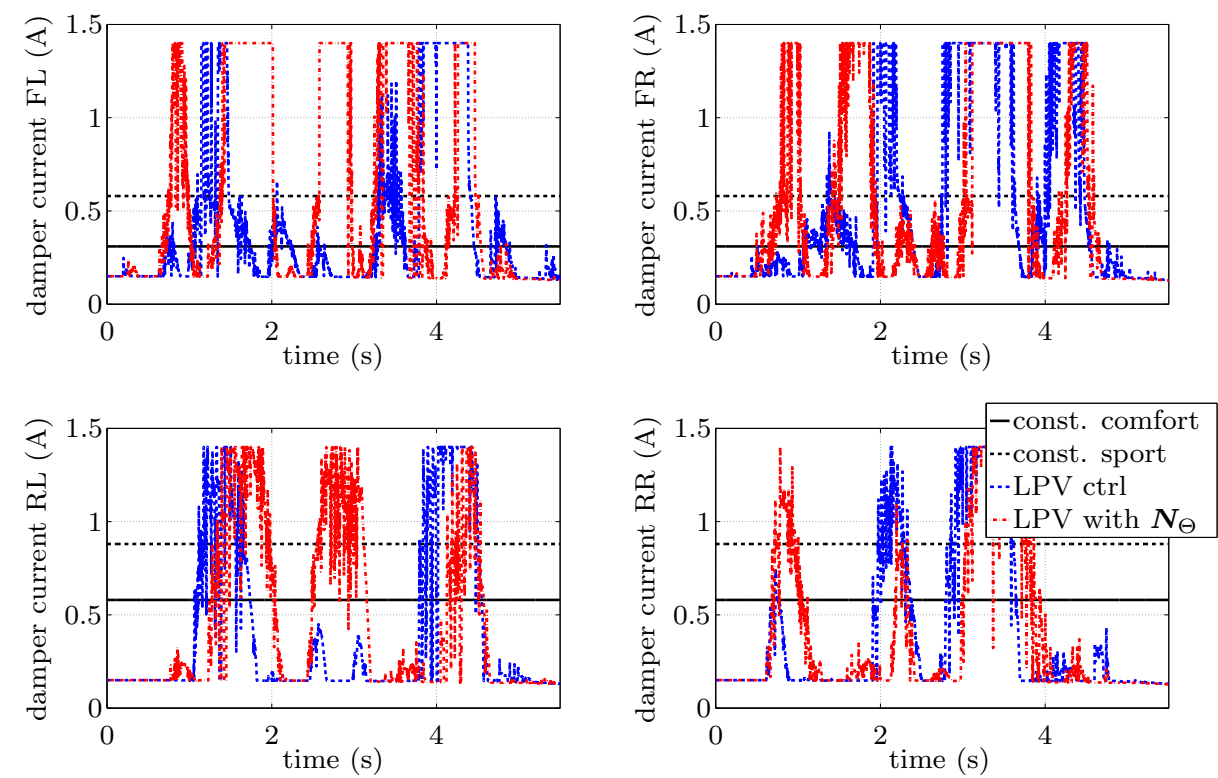

Figure 16: ISO3888-2: Double lane change at a vehicle speed of $50 \mathrm{~km} / \mathrm{h}$; top left - damper current front left, top right - damper current front right, bottom left - damper current rear left, and bottom right - damper current rear right

lem and aims at an attenuation of the effect of driver-induced roll disturbances on ride comfort and vehicle handling. Equally to the LPV feedback control design, the feedforward filter employs saturation indicator parameters the incorporate the restrictive force constraints of semi-active dampers in the LPV design. In this way, the control signal of the feedforward filter also linearly reduces in the event of saturation depending on the saturation indicators. The resulting two-degree-of-freedom controller features guaranteed stability for all admissible saturation indicators. Moreover, the equal saturation indicator dependent weighting schemes of the feedback and feedforward control design achieve equal priority of the feedback controller and the feedforward filter over the constrained control signal.

The proposed two-degree-of-freedom LPV controller is validated by lane change experiments. The results show a vital improvement of ride comfort and vehicle handling compared to the LPV controller without feedforward filter. 


\section{Acknowledgment}

The authors thank Uwe Bleck for his great job as the test driver and Ricardo Pinto de Castro for his advice on vehicle dynamics control.

\section{References}

[1] M. Mitschke, H. Wallentowitz, Dynamik der Kraftfahrzeuge, 4th Edition, VDI-Buch, Springer-Verlag, Heidelberg, 2004. doi:10.1007/978-3-658-05068-9.

[2] E. Guglielmino, T. Sireteanu, C. W. Stammers, G. Ghita, M. Giuclea, Semiactive Suspension Control, 1st Edition, Springer-Verlag, London, 2008. doi:10.1007/978-1-84800-231-9

[3] S. M. Savaresi, C. Poussot-Vassal, L. Dugard, O. Sename, C. Spelta, SemiActive Suspension Control Design for Vehicles, 1st Edition, Elsevier, Oxford, 2010.

[4] H. E. Tseng, D. Hrovat, State of the art survey: active and semi-active suspension control, Vehicle System Dynamics 53 (7) (2015) 1034-1062. doi:10.1080/00423114.2015.1037313.

[5] D. E. Williams, W. M. Haddad, Active suspension control to improve vehicle ride and handling, Vehicle System Dynamics 28 (1) (1997) 1-24. doi:10.1080/00423119708969346.

[6] P. Brezas, M. C. Smith, Linear quadratic optimal and risk-sensitive control for vehicle active suspensions, IEEE Transactions on Control Systems Technology 22 (2) (2014) 543-556. doi:10.1109/TCST.2013.2253556.

[7] M. C. Smith, F.-C. Wang, Controller parameterization for disturbance response decoupling: application to vehicle active suspension control, IEEE Transactions on Control Systems Technology 10 (3) (2002) 393-407. doi:10.1109/87.998029. 
[8] P. Brezas, M. C. Smith, W. Hoult, A clipped-optimal control algorithm for semi-active vehicle suspensions: Theory and experimental evaluation, $\mathrm{Au}-$ tomatica 53 (2015) 188-194. doi:10.1016/j.automatica.2014.12.026.

[9] M. Ahmadian, D. E. Simon, Can semiactive dampers with skyhook control improve roll stability of passenger vehicles?, in: SAE Technical Paper, SAE International, 2004. doi:10.4271/2004-01-2099.

[10] E. Prempain, I. Postlethwaite, Feedforward control: a fullinformation approach, Automatica $37 \quad$ (1) (2001) 17-28.

380 doi:10.1016/S0005-1098(00)00118-7

[11] C. Poussot-Vassal, O. Sename, L. Dugard, P. Gáspár, Z. Szabó, J. Bokor, A new semi-active suspension control strategy through LPV technique, Control Engineering Practice 16 (12) (2008) 1519-1534. doi:10.1016/j.conengprac.2008.05.002

385 [12] A.-L. Do, O. Sename, L. Dugard, An LPV control approach for semi-active suspension control with actuator constraints, in: Proc. of the American Control Conference (ACC), Baltimore, Maryland, USA, 2010, pp. 46534658. doi:10.1109/ACC.2010.5531069.

[13] F. Wu, K. M. Grigoriadis, A. Packard, Anti-windup controller design using linear parameter-varying control methods, Int. J. of Control 73 (12) (2000) 1104-1114. doi:10.1080/002071700414211.

[14] M. Fleps-Dezasse, F. Svaricek, J. Brembeck, Design and experimental assessment of an active fault-tolerant lpv vertical dynamics controller, IEEE Trans. on Control Systems Technology PP (99) (2018) 1-8. doi:10.1109/TCST.2018.2796066.

[15] M. Fleps-Dezasse, F. Svaricek, J. Brembeck, Damper fault-tolerant linear parameter-varying semi-active suspension control, in: Proc. of the IFAC World Congress (WC), Toulouse, France, 2017, pp. 8592-8599. doi:10.1016/j.ifacol.2017.08.1425 
400 [16] E. Prempain, I. Postlethwaite, A new two-degree-of-freedom gain scheduling method applied to the lynx mk7, Proc. of the Institution of Mechanical Engineers, Part I: Journal of Systems and Control Engineering 214 (4) (2000) 299-311. doi:10.1243/0959651001540654

[17] J. Theis, H. Pfifer, A. Knoblach, F. Saupe, H. Werner, Linear parametervarying feedforward control: A missile autopilot design, in: Proc. of the AIAA Conf. on Guidance, Navigation, and Control, Kissimmee, Florida, 2015, pp. 1-9. doi:10.2514/6.2015-2001.

[18] J. Mohammadpour, C. W. Scherer, Control of Linear Parameter Varying Systems with Applications, 1st Edition, Springer US, New York, 2012. doi:10.1007/978-1-4614-1833-7.

[19] O. Sename, P. Gáspár, J. Bokor, Robust Control and Linear Parameter Varying Approaches: Application to Vehicle Dynamics, 1st Edition, Springer, Berlin, Heidelberg, 2013. doi:10.1007/978-3-642-36110-4.

[20] A. Unger, F. Schimmack, B. Lohmann, R. Schwarz, Application of LQbased semi-active suspension control in a vehicle, Control Engineering Practice 21 (12) (2013) 1841-1850. doi:10.1016/j .conengprac.2013.06.006.

[21] J. Lu, M. DePoyster, Multiobjective optimal suspension control to achieve integrated ride and handling performance, IEEE Transactions on Control Systems Technology 10 (6) (2002) 807-821. doi:10.1109/TCST.2002.804121.

[22] M. Fleps-Dezasse, M. M. Ahmed, J. Brembeck, F. Svaricek, Experimental evaluation of linear parameter-varying semi-active suspension control, in: Proc. of the IEEE Int. Conf. on Control Applications (CCA), Buenos Aires, Argentina, 2016, pp. 77-84. doi:10.1109/CCA.2016.7587825.

[23] K. Zhou, J. C. Doyle, K. Glover, Robust and Optimal Control, Prentice Hall, Upper Saddle River, N.J., 1996. 
[24] J. C. Doyle, K. Glover, P. P. Khargonekar, B. A. Francis, State-space solutions to standard $H_{2}$ and $H_{\infty}$ control problems, IEEE Transactions on Automatic Control 34 (8) (1989) 831-847. doi:10.1109/9.29425.

[25] H. Kwakernaak, Robust control and $h_{\infty}$-optimization - tutorial paper, Automatica 29 (2) (1993) 255-273. doi:10.1016/0005-1098(93)90122-A

[26] S. Skogestad, I. Postlethwaite, Multivariable Feedback Control: Analysis and Design, 2nd Edition, Wiley-Blackwell, Chichester, 2005.

[27] A. Hjartarson, P. J. Seiler, A. Packard, G. J. Balas, LPV aeroservoelastic control using the LPVTools toolbox, in: Proc. of the AIAA Atmospheric Flight Mechanics (AFM) Conf., Boston, MA., USA, 2013, pp. 139-145. doi:10.2514/6.2013-4742

[28] A. Hjartarson, P. J. Seiler, A. Packard, LPVTools: A toolbox for modeling, analysis, and synthesis of parameter varying control systems, in: Proc. of the 1st IFAC Workshop on Linear Parameter Varying Systems (LPVS), Grenoble, France, 2015, pp. 139-145. doi:10.1016/j.ifacol.2015.11.127

[29] G. Becker, A. Packard, Robust performance of linear parametrically varying systems using parametrically-dependent linear feedback, Systems \& Control Letters 23 (3) (1994) 205-215. doi:10.1016/0167-6911(94)90006-X.

[30] F. Wu, Control of linear parameter varying systems, Ph.D. thesis, Engineering-Mechanical Engineering, Berkeley (1995).

[31] F. Wu, X. H. Yang, A. Packard, G. Becker, Induced $L_{2}$-norm control for LPV systems with bounded parameter variation rates, Int. J. of Robust and Nonlinear Control 6 (9-10) (1996) 983-998. doi:10.1002/(SICI) 1099-1239(199611) 6:9/10<983.

[32] Mechanical vibration and shock - evaluation of human exposure to wholebody vibration - part 1: General requirements, Standard, International Organization for Standardization (2631-1:1997). 
${ }_{455}$ [33] D. E. Williams, W. M. Haddad, Nonlinear control of roll moment distribution to influence vehicle yaw characteristics, IEEE Transactions on Control Systems Technology 3 (1) (1995) 110-116. doi:10.1109/87.370716.

[34] M. Otter, Multi-domain Modeling and Simulation, Springer, London, 2013, pp. 1-14. doi:10.1007/978-1-4471-5102-9_140-1.

460 [35] Passenger cars - test track for a severe lane-change manoeuvre - part 2: Obstacle avoidance, Standard, International Organization for Standardization (3888-2:2011).

[36] D. Schramm, M. Hiller, R. Bardini, Vehicle Dynamics: Modeling and Simulation, 1st Edition, Springer-Verlag, Heidelberg, 2014.

465 doi:10.1007/978-3-540-36045-2. 


\section{Dear Editor and Reviewer}

We would like to thank the reviewers and the AE for their helpful comments and suggestions regarding our manuscript. We appreciate that our paper is provisionally accepted for publication in your journal and we look forward to integrate the final remarks such that the paper can be publish.

The remarks of the reviewers have been addressed as described below. The original remarks of the reviewers are written in italics and our reply in standard font.

Best regards

The authors

\section{Comment}

Associate Editor:

The paper is near ready for publication. It is beneficial if you make a minor update of the lower saturation indicator, and resubmit.

Reviewer \#3: I have got correct answers partly to my questions and proposals.

Unfortunately, the handling of the saturation indicator with small value $u_{-} i$ is not reassuring. Perhaps the appropriate selection of $u_{-} i^{\wedge} \min$ would be adequate.

In order to present a reassuring explanation how the assumption on $u_{-} i^{\wedge} \min$ of the saturation indicator concept are satisfied in the current application with a semi-active damper, we extended the discussion of the transformation to a virtual control signal right after eq (7). 
LaTeX Source Files
Click here to download LaTeX Source Files: Latex Source Files - final.zip

LaTeX Source Files
Click here to download LaTeX Source Files: Latex Source Files - final.zip Click here to download LaTex Source Files: Latex Source Files - final.zip

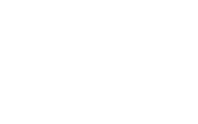
(1)

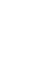
(n) (1) (1) (1) (1) (1) (1) . . . . . . . . . . . . . 